\title{
Avaliação de pirogênios em produtos de uso veterinário pelos testes da hipertermia em coelhos e do lisado de amebócitos do Limulus
}

\author{
Pyrogens in veterinary products by the rabbit pyrogen test \\ and the Limulus amoebocyte lysate test
}

\author{
Thiago Barth ${ }^{\mathrm{I}}$ Volmir João Dalmora' ${ }^{\mathrm{II}}$ Felipe Bianchini D’Avila' \\ Sérgio Luiz Dalmora ${ }^{{ }^{*}}$
}

\section{RESUMO}

Realizou-se a avaliação de pirogênios em produtos veterinários de uso parenteral, pelo método da hipertermia em coelhos, calculando-se, para o teste das amostras, doses com concentrações de três a sete vezes superiores à terapêutica. Preconizou-se como resposta positiva o aumento de temperatura de $0,6^{\circ} \mathrm{C}$. Utilizou-se também o ensaio do lisado de amebócitos do Limulus ( $L A L)$ por geleificação, semiquantitativo, executando o teste de interferentes, validando o procedimento e estabelecendo a máxima diluição válida para a análise de cada produto. Paralelamente, efetuou-se avaliação comparativa de amostras com o método do LAL cromogênico, quantitativo, demonstrando correlação $e$ reprodutibilidade dos resultados. Avaliaram-se vinte e oito produtos de diferentes classes farmacológicas, observando-se que dois não cumpriram as especificações, sendo reprovados. Sugere-se que as especificações estudadas sejam adotadas, contribuindo para aprimorar o controle de contaminantes, garantindo a qualidade e a segurança dos produtos veterinários.

Palavras-chave: coelhos, pirogênios, teste da hipertermia, teste do lisado de amebócitos do Limulus.

\section{ABSTRACT}

The rabbit pyrogen test was used to evaluate veterinary products, suggesting the temperature rise of $0.6^{\circ} \mathrm{C}$ as the ending point for the positive results. The test doses were calculated based on the therapeutic dose increased from three to seven times. The semi-quantitative Limulus amoebocyte lysate (LAL) gel clot test was performed and compared to the LAL spectrophotometric chromogenic, quantitative assay. The comparative evaluation of the samples showed correlation and reproducibility of the results. The interference test was carried out, the procedure validated and the maximum valid dilution established for the analysis of the products without
Pharmacopoeial specifications. Two of the twenty-eight products of different pharmacological groups evaluated didn't meet the requirements and were reproved. The specifications investigated are suggested to be used for the purity evaluation of the veterinary parenteral products, as a contribution to assure the quality and safety of the products.

Key words: rabbit, pyrogens, temperature rise test, Limulus amoebocyte lysate test.

\section{INTRODUÇÃO}

Os pirogênios podem originar-se de bactérias gram-negativas, gram-positivas, de fungos e de vírus. Os monócitos/macrófagos reagem aos componentes microbianos, induzindo a liberação de pirogênios endógenos, como prostaglandinas e as citocinas pró-inflamatórias: interleucina-1, interleucina-6 e fator de necrose tumoral- $\alpha$. As endotoxinas bacterianas são lipopolissacarídios complexos de alta massa molecular $\left(\sim 10^{6} \mathrm{Da}\right)$ que constituem a parede celular de bactérias gram-negativas e são formadas pelo núcleo polissacarídico, ao qual se liga a cadeia $\mathrm{O}$-antigênica e a unidade lipídica A, que é responsável pelas propriedades pirogênicas. São as mais comumente encontradas em produtos injetáveis de uso veterinário e humano. Os pirogênios são quimicamente heterogêneos e podem apresentar composição e estrutura variável, as quais influenciam os efeitos biológicos como febre, alteração do quadro leucocitário e choque séptico(KLUGER, 1991; RIETSCHEL et al., 1994; HENDERSON et al., 1996).

IDepartamento de Farmácia Industrial, Universidade Federal de Santa Maria, (UFSM), 97105-900, Santa Maria, RS, Brasil. E-mail: sdalmora@ccs.ufsm.br. * Autor para correspondência

IIDepartamento de Ciências Biológicas, Universidade do Contestado, Concórdia, SC, Brasil. 
O teste da hipertermia em coelhos, baseado na injeção intravenosa de soluções sob pesquisa, tem sido amplamente usado para o controle da qualidade de preparações parenterais. A resposta positiva é avaliada através da elevação da temperatura em $0,5 \mathrm{ou}$ $0,6^{\circ} \mathrm{C}$, segundo a literatura adotada (EP., 2002; HOFFMANN et al., 2005). É um teste in vivo que expressa os efeitos fisiopatológicos induzidos pelos pirogênios, porém é qualitativo, tem baixa sensibilidade, não pode ser usado para fármacos que interferem com a resposta pirogênica e utiliza animais, cuja substituição ou redução é recomendada (HOFFMANN et al., 2005).

Por sua vez, as observações de que preparações de endotoxinas de Escherichia coli causavam coagulação extracelular do sangue do caranguejo Limulus polyphemus fundamentaram o desenvolvimento do teste do lisado de amebócitos do Limulus (LAL) in vitro, específico e altamente sensível para detectar endotoxinas de bactérias gram-negativas (LEVIN \& BANG, 1964). O teste pode apresentar resultados falsos (negativo ou positivo) com alguns produtos, antibióticos e vacinas virais (FENNRICH et al., 1999; POOLE \& GAINES DAS, 2001).

Os testes da hipertermia em coelhos e do LAL são recomendados pela Farmacopéia Britânica Veterinária (B.P. Vet., 2003), que oficializa também as especificações descritas pela Européia (EP., 2002). Esses testes são essenciais para o controle de contaminantes pirogênicos nos produtos injetáveis e para a validação das metodologias sob investigação, baseadas no uso de linhagens celulares (MOESBY et al., 1999), na cultura de sangue total ou de monócitos de sangue humano (FENNRICH et al., 1999; ANDRADE et al., 2003).

O presente trabalho teve por objetivo realizar a avaliação de pirogênios em medicamentos veterinários de uso parenteral, pelos testes da hipertermia em coelhos, e do LAL, sugerindo doses e especificações que contribuem para aprimorar o controle da qualidade e da segurança dos produtos.

\section{MATERIAL E MÉTODOS}

Padrão de referência, reagentes e produtos veterinários Utilizou-se o segundo padrão internacional de endotoxinas bacterianas, contendo 10.000 unidades endotóxicas (UE) /ampola (WHO 94/580), doado pelo National Institute for Biological Standards and Control (Inglaterra). Utilizou-se reagente lisado de amebócitos do Limulus com sensibilidade de 0,06UE $\mathrm{ml}^{-1}$, Cape Code (EUA) e Biowhittaker (EUA), e também novo azul de metileno, Sigma (EUA). Produtos veterinários injetáveis, disponíveis comercialmente, foram selecionados, observando-se o lote e prazo de validade, e identificados nas tabelas respectivas com base na substância ativa e na concentração, acrescentando-se também as seguintes associações: A - dipropionato de imidocarb $120 \mathrm{mg}$ e vitamina B12 $0,024 \mathrm{mg}$ por $\mathrm{ml}$; B - enrofloxacino $100 \mathrm{mg}$ e piroxicam $12 \mathrm{mg}$ por $\mathrm{ml}$; $\mathrm{C}$ - penicilinas $\mathrm{G}$ procaína 1.500.000UI, potássica 1.500.000UI, benzatina 3.000.000UI e estreptomicina 2,5g por frasco; D - penicilina $\mathrm{G}$ procaína $200.000 \mathrm{UI}$, estreptomicina $80 \mathrm{mg}$ e piroxicam $6 \mathrm{mg}$ por $\mathrm{ml}$; E - Solução: ácido bórico 40mg, gluconato de cálcio $230 \mathrm{mg}$, cloreto de magnésio $1,6 \mathrm{mg}$, glicerofosfato de sódio $30 \mathrm{mg}$, efedrina $0,5 \mathrm{mg}$ e glicose $30 \mathrm{mg}$ por $\mathrm{ml} ; \mathrm{F}$ sulfadiazina $400 \mathrm{mg}$ e trimetoprima $80 \mathrm{mg}$ por $\mathrm{ml} ; \mathrm{G}-$ sulfadoxina $200 \mathrm{mg}$, trimetoprima $40 \mathrm{mg}$ e piroxicam $12 \mathrm{mg}$ porml.

Animais

Foram usados coelhos machos e fêmeas da linhagem Nova Zelândia, provenientes do Biotério Central da Universidade Federal de Santa Maria (UFSM).

Teste da hipertermia em coelhos

$\mathrm{O}$ teste foi executado de acordo com as recomendações da literatura (F.BRAS., 1988; EP., 2002), adotando-se as especificações farmacopéicas disponíveis, injetando-se três coelhos com cada amostra e registrando-se o aumento individual de temperatura durante três horas consecutivas. Para os demais produtos, calcularam-se as dosagens com base na maior posologia recomendada por $\mathrm{kg}$ de massa corporal, pelo Laboratório Produtor. Para as associações com composição expressa em massa, somaram-se os teores das substâncias ativas presentes na dosagem sugerida e estabeleceu-se a dose inicial. Por sua vez, para as formulações com composição declarada em unidades e miligramas, avaliou-se a quantidade de cada componente na dosagem terapêutica, planejando-se o teste com base na indicação farmacológica do produto e no fármaco presente em maior teor, usando-se sua expressão de potência para a especificação. Em ambos os casos, as doses foram especificadas com concentrações aproximadas, três a sete vezes superiores à terapêutica, conforme a tabela 1.

Validou-se o procedimento para produtos com excipientes oleosos por via subcutânea, designando-se três grupos de animais, respectivamente, para controle positivo, amostra e amostra contaminada com a dose pirogênica equivalente a $15 \mathrm{UE} \mathrm{ml}^{-1} \mathrm{~kg}^{-1} \mathrm{do}$ segundo padrão internacional de endotoxinas bacterianas (SILVEIRA et al., 2004). Prolongou-se o tempo de leitura, registrando-se as respostas correspondentes durante quatro horas.

Teste do lisado de amebócitos do Limulus (LAL)

Calculou-se o limite de endotoxinas bacterianas (LEC) para produtos veterinários de uso 
parenteral, sem especificações farmacopéicas, com base na dose terapêutica, pela equação: $L E C=\mathrm{K} / \mathrm{M}$, em que $\mathrm{K}=$ menor dose pirogênica por $\mathrm{kg}$ de peso animal, igual a $5 \mathrm{UE} \mathrm{kg}^{-1} \mathrm{e} \mathrm{M}=$ dose máxima do produto recomendada por kg de peso no período de uma hora. Calculou-se a máxima diluição válida (MDV), que deve apresentar resposta negativa, e realizou-se o teste para confirmação da sensibilidade do reagente LAL.

Teste de interferentes e validação

Realizou-se o teste de inibição/ potencialização da resposta pela adição do segundo padrão internacional de endotoxinas bacterianas a diferentes diluições de cada produto veterinário, inferiores a MDV, que, em teste anterior, haviam fornecido resultado negativo, mas que se tornaram positivas após a contaminação. A média geométrica (M) para as soluções foi calculada pela equação $\mathrm{M}=$ $\operatorname{antilog}\left(\sum e / f\right)$, em que $\sum e=$ soma dos logaritmos da menor concentração de endotoxinas com reação positiva em cada série de diluições da amostra e $f=$ número de replicatas. Considerou-se a amostra sem fatores interferentes quando a sensibilidade do $\mathrm{LAL}$ $(\lambda)$, determinada na presença da solução do produto, foi igual ou maior que $0,5 \lambda$ e igual ou menor que $2 \lambda$ (EP., 2002; SILVEIRA et al., 2004).

\section{Ensaio por geleificação}

O ensaio foi realizado em placas de Petri ou em tubos de ensaio (SILVEIRA et al., 2004), ajustandose os volumes dos reagentes e mantendo-se a relação constante. Em placa de polietileno, adicionaram-se, em duplicata, $10 \mu 1$ do reagente LAL e $10 \mu 1$ de cada diluição da amostra ou padrão. Incubou-se em estufa a $37 \pm 1^{\circ} \mathrm{C}$ por uma hora. Para leitura da formação de gel, adicionou-se $1 \mu \mathrm{l}$ da solução de novo azul de metileno $0,2 \%$ sobre cada ponto de reação, observando-se sua mistura (reação negativa) ou distribuição na superfície do gel (reação positiva). Calculou-se o resultado, multiplicando-se a maior diluição, na qual a resposta foi positiva, e a menor diluição, na qual foi negativa, pela sensibilidade do reagente LAL. Esses valores representam a faixa de concentração de endotoxinas bacterianas em unidades endotóxicas.

\section{Ensaio cromogênico \\ O ensaio foi realizado em microplacas de 96} cavidades a $37 \pm 1^{\circ} \mathrm{C}$ (EP., 2002), adicionando-se $50 \mu 1$ do padrão ou das amostras, respectivamente. Acrescentaram-se, então, $50 \mu 1$ da solução de lisado de amebócitos do Limulus e procedeu-se à incubação da microplaca por 10 minutos a $37 \pm 1^{\circ} \mathrm{C}$. A seguir, foram pipetados $100 \mu 1$ da solução de substrato cromogênico e, após seis minutos de incubação a $37 \pm 1^{\circ} \mathrm{C}$, interrompeu-se a reação pela adição de $100 \mu 1$ de ácido acético $25 \%$. A absorbância foi medida em leitor de placas a $405 \mathrm{~nm}$, os valores projetados na curva de endotoxinas padrão e os resultados expressos em UE $\mathrm{ml}^{-1}$.

\section{RESULTADOS}

Realizou-se o teste em coelhos, registrandose os aumentos individuais de temperatura, concluindo-se pela aprovação ou reprovação de cada fármaco com base nas especificações estabelecidas, conforme mostra a tabela 1. Do mesmo modo, foram avaliadas as amostras de florfenicol e ivermectina, em veículo oleoso, que forneceram resultados negativos.

Para o teste do LAL por geleificação, confirmou-se a sensibilidade do reagente do LAL de $0,06 \mathrm{UE} \mathrm{ml}^{-1} \mathrm{e}$, então, determinou-se a menor diluição aceitável e validou-se o teste para os produtos da tabela 2 , na qual se observa a média geométrica entre $\geq 0,5 \lambda \mathrm{e} \leq 2 \lambda$, com recuperação de 50 a $200 \%$ em relação à sensibilidade especificada, bem como os resultados obtidos.

Pode-se observar, nas tabelas 1 e 2, que alguns produtos, por cumprirem os requisitos do teste do LAL, foram submetidos a avaliação pelos dois métodos, demonstrando a concordância das respostas

Tabela 1 - Concentrações injetadas e resultados do teste da hipertermia em coelhos, em produtos veterinários de uso parenteral.

\begin{tabular}{|c|c|c|}
\hline Fármacos & Doses $\mathrm{kg}^{-1}$ & Resultado \\
\hline Abamectina $10 \mathrm{mg} \mathrm{ml}^{-1}$ & $0,6 \mathrm{mg} / \mathrm{ml}$ & Aprovado \\
\hline Bromexina $30 \mathrm{mg} / \mathrm{ml}^{-1}$ & $0,9 \mathrm{mg} / \mathrm{ml}$ & Aprovado \\
\hline Ceftiofur 50 $\mathrm{mg} \mathrm{ml}^{-1}$ & $15 \mathrm{mg} / 5 \mathrm{ml}$ & Aprovado \\
\hline Cetoprofeno $100 \mathrm{mg} \mathrm{ml}^{-1}$ & $9 \mathrm{mg} / \mathrm{ml}$ & Aprovado \\
\hline Dexametasona $2 \mathrm{mg} \mathrm{ml}^{-1}$ & $0,15 \mathrm{mg} / \mathrm{ml}$ & Aprovado \\
\hline Enrofloxacino $25 \mathrm{mg} \mathrm{ml}^{-1}$ & $7,5 \mathrm{mg} / \mathrm{ml}$ & Aprovado \\
\hline Florfenicol $300 \mathrm{mg} \mathrm{ml}^{-1}$ & $150 \mathrm{mg} / \mathrm{ml}^{*}$ & Aprovado \\
\hline Flumetasona $0,5 \mathrm{mg} \mathrm{ml}^{-1}$ & $0,063 \mathrm{mg} / \mathrm{ml}$ & Aprovado \\
\hline Furosemida $10 \mathrm{mg} \mathrm{ml}^{-1}$ & $0,75 \mathrm{mg} / \mathrm{ml}$ & Aprovado \\
\hline Heparina 5000UI ml ${ }^{-1}$ & $2000 \mathrm{UI} / \mathrm{ml}$ & Aprovado \\
\hline Ivermectina $10 \mathrm{mg} \mathrm{ml}^{-1}$ & $1 \mathrm{mg} / \mathrm{ml}^{*}$ & Aprovado \\
\hline Levamisol $75 \mathrm{mg} \mathrm{ml}^{-1}$ & $20 \mathrm{mg} / \mathrm{ml}$ & Aprovado \\
\hline Metoclopramida $5 \mathrm{mg} \mathrm{ml}^{-1}$ & $3 \mathrm{mg} / \mathrm{ml}$ & Aprovado \\
\hline Oxitetraciclina $200 \mathrm{mg} \mathrm{m}^{-1}$ & $5 \mathrm{mg} / \mathrm{ml}^{1}$ & Aprovado \\
\hline $\begin{array}{l}\text { Sulfóxido de albendazol } \\
150 \mathrm{mg} \mathrm{ml}^{-1}\end{array}$ & $10 \mathrm{mg} / 2 \mathrm{ml}$ & Aprovado \\
\hline Associação A & $15 \mathrm{mg} / \mathrm{ml}$ & Aprovado \\
\hline Associação B & $30 \mathrm{mg} / \mathrm{ml}$ & Aprovado \\
\hline Associação C & $4000 \mathrm{UI} / \mathrm{ml}$ & Reprovado** \\
\hline Associação D & $4000 \mathrm{UI} / \mathrm{ml}$ & Aprovado \\
\hline Associação E & $996 \mathrm{mg} / 6 \mathrm{ml}$ & Reprovado** \\
\hline Associação F & $2160 \mathrm{mg} / 3 \mathrm{ml}$ & Aprovado \\
\hline Associação G & $100 \mathrm{mg} / \mathrm{ml}$ & Aprovado \\
\hline
\end{tabular}

*Via subcutânea; ${ }^{1}$ B.P. Veterinária. **Reprovado=presença de pirogênios.

Ciência Rural, v.37, n.1, jan-fev, 2007. 
Tabela 2 - Resultados do teste de inibição/potencialização e avaliação de produtos veterinários pelo ensaio do lisado de amebócitos do Limulus (LAL), com sensibilidade de 0,06 UE/ml.

\begin{tabular}{|c|c|c|c|c|c|c|}
\hline \multirow{2}{*}{ Fármacos } & \multirow{2}{*}{$\begin{array}{l}\text { Máxima } \\
\text { diluição } \\
\text { válida }\end{array}$} & \multirow{2}{*}{$\begin{array}{l}\text { Menor } \\
\text { diluição } \\
\text { válida }\end{array}$} & \multirow{2}{*}{$\begin{array}{l}\text { Média } \\
\text { UE/ml }\end{array}$} & \multirow{2}{*}{ Limite de endotoxinas } & \multicolumn{2}{|c|}{ Resultado } \\
\hline & & & & & $\mathrm{UE} / \mathrm{ml}$ & Final \\
\hline Amoxicilina $150 \mathrm{mg} \mathrm{ml}^{-1}$ & $1: 625$ & $1: 32$ & 0,06 & $0,25 \mathrm{UE} / \mathrm{mg}^{2}$ & $<0,06$ & $\mathrm{~A}$ \\
\hline Bromexina $30 \mathrm{mg} \mathrm{ml}^{-1}$ & $1: 833$ & $1: 64$ & 0,04 & $16 \mathrm{UE} / \mathrm{mg}^{1}$ & $<0,06$ & $\mathrm{~A}$ \\
\hline Cetoprofeno $100 \mathrm{mg} \mathrm{ml}^{-1}$ & $1: 283$ & $1: 32$ & 0,03 & $1,7 \mathrm{UE} / \mathrm{mg}^{1}$ & $0,96-1,92$ & $\mathrm{~A}$ \\
\hline Dexametasona $2 \mathrm{mg} \mathrm{ml}^{-1}$ & $1: 3333$ & $1: 32$ & 0,04 & $100 \mathrm{UE} / \mathrm{mg}^{1}$ & $<0,06$ & $\mathrm{~A}$ \\
\hline Dipirona $500 \mathrm{mg} \mathrm{ml}^{-1}$ & $1: 5833$ & $1: 8$ & 0,03 & $0,7 \mathrm{UE} / \mathrm{mg}^{1}$ & $<0,06$ & $\mathrm{~A}$ \\
\hline Enrofloxacino $25 \mathrm{mg} \mathrm{ml}^{-1}$ & $1: 416$ & $1: 32$ & 0,06 & $1 \mathrm{UE} / \mathrm{mg}^{1}$ & $<0,06$ & $\mathrm{~A}$ \\
\hline Fenilbutazona $200 \mathrm{mg} \mathrm{ml}^{-1}$ & $1: 416$ & $1: 32$ & 0,06 & $0,125 \mathrm{UE} / \mathrm{mg}^{1}$ & $0,06-0,12$ & $\mathrm{~A}$ \\
\hline Florfenicol $992 \mathrm{mcg} \mathrm{mg}^{-1}$ & $1: 625$ & $1: 16$ & 0,06 & $0,125 \mathrm{UE} / \mathrm{mg}^{1}$ & $0,06-0,12$ & $\mathrm{~A}$ \\
\hline Flumetasona $0,5 \mathrm{mg} \mathrm{ml}^{-1}$ & $1: 3333$ & $1: 8$ & 0,03 & $400 \mathrm{UE} / \mathrm{mg}^{1}$ & $<0,06$ & $\mathrm{~A}$ \\
\hline Furosemida $10 \mathrm{mg} \mathrm{ml}^{-1}$ & $1: 583$ & $1: 64$ & 0,04 & $3,5 \mathrm{UE} / \mathrm{mg}^{2}$ & $0,12-0,24$ & $\mathrm{~A}$ \\
\hline Gentamicina $40 \mathrm{mg} \mathrm{ml}^{-1}$ & $1: 1113$ & $1: 128$ & 0,06 & $1,67 \mathrm{UE} / \mathrm{mg}^{2}$ & $<0,06$ & $\mathrm{~A}$ \\
\hline Heparina 5000UI ml ${ }^{-1}$ & $1: 2500$ & $1: 8$ & 0,03 & $0,03 \mathrm{UE} / \mathrm{UI}^{1}$ & $<0,06$ & $\mathrm{~A}$ \\
\hline Levamisol $75 \mathrm{mg} \mathrm{ml}^{-1}$ & $1: 1662$ & $1: 512$ & 0,03 & $1,33 \mathrm{UE} / \mathrm{mg}^{1}$ & $<0,06$ & A \\
\hline Metoclopramida $5 \mathrm{mg} \mathrm{ml}^{-1}$ & $1: 416$ & $1: 16$ & 0,03 & $5 \mathrm{UE} / \mathrm{mg}^{1}$ & $0,12-0,24$ & $\mathrm{~A}$ \\
\hline Ocitocina $10 \mathrm{UI} \mathrm{ml} \mathrm{m}^{-1}$ & $1: 8333$ & 0 & 0,04 & $50 \mathrm{UE} / \mathrm{UI}^{1}$ & $<0,06$ & $\mathrm{~A}$ \\
\hline Xilazina $20 \mathrm{mg} \mathrm{ml}^{-1}$ & $1: 5533$ & $1: 2$ & 0,06 & $16,6 \mathrm{UE} / \mathrm{mg}^{1}$ & $3,84-7,68$ & $\mathrm{~A}$ \\
\hline Associação C & $1: 500$ & $1: 16$ & 0,06 & $0,01 \mathrm{UE} / 100 \mathrm{UI}$ Penicilina $\mathrm{G}^{1}$ & $61-122$ & $\mathrm{R}$ \\
\hline Associação D & $1: 333$ & $1: 128$ & 0,06 & $0,01 \mathrm{UE} / 100 \mathrm{UI}$ Penicilina $\mathrm{G}^{1}$ & $<0,06$ & A \\
\hline Associação E & $1: 83$ & 0 & 0,06 & $0,015 \mathrm{UE} / \mathrm{mg}^{1}$ & $491-983$ & $\mathrm{R}$ \\
\hline Associação F & $1: 1600$ & $1: 32$ & 0,03 & $0,2 \mathrm{UE} / \mathrm{mg}^{1}$ & $<0,06$ & A \\
\hline Associação G & $1: 1000$ & $1: 128$ & 0,03 & $0,3 \mathrm{UE} / \mathrm{mg}^{1}$ & $<0,06$ & A \\
\hline
\end{tabular}

${ }^{1}$ Calculado - DFI; ${ }^{2}$ EP., 2002; UE=unidades endotóxicas; A=aprovado; R=reprovado (presença de pirogênios).

e a vantagem de cada procedimento, qualitativo e semiquantitativo.

Realizou-se também a avaliação comparativa de diferentes produtos veterinários pelo teste do LAL com leitura da resposta por geleificação, semiquantitativa, e cromogênica espectrofotométrica, quantitativa. A tabela 3 mostra a reprodutibilidade e a concordância dos resultados de acordo com as especificidades de cada procedimento.

\section{DISCUSSÃO}

Os testes de pirogênios são necessários para avaliar-se a contaminação de fármacos, produtos veterinários injetáveis e materiais de uso hospitalar. Executou-se o teste da hipertermia em coelhos, também preconizado para medicamentos de uso humano, adotando-se como resposta positiva o aumento de temperatura de $0,6^{\circ} \mathrm{C}$ (HOFFMANN et al., 2005). Observa-se que as doses-teste foram planejadas com base na dosagem terapêutica, aumentada a fim de detectar-se, com maior segurança, possíveis contaminantes através de seu efeito farmacológico. Para produtos com veículos oleosos, usados em preparações de ação prolongada, é sugerida, preferencialmente, a avaliação dos componentes da formulação, ou, havendo necessidade, do produto acabado. As amostras não cumpriram os parâmetros de validação do teste do LAL, sendo então submetidas ao ensaio em coelhos, como mostra a tabela 1 .
O método do lisado de amebócitos do Limulus (LAL) foi validado, sempre que possível, para cada medicamento sob estudo, pois podem ser encontrados resultados falsos, devidos à interferência da substância ativa ou dos componentes da formulação, estabelecendo-se as especificações descritas na tabela 2. Além disso, justificam-se os experimentos comparativos com o método cromogênico, pois rotineiramente tem sido adotado o método por geleificação, por sua simplicidade e custo, cumprindo os requisitos do controle da qualidade (EP., 2002), em especial da área veterinária (BRASIL, 2004).

Conclui-se este trabalho, destacando a importância do método da hipertermia em coelhos para a avaliação especialmente de associações de fármacos largamente empregadas na área veterinária, bem como do teste do LAL in vitro, que se constitui um método de escolha com vantagens para os produtos que cumprem os parâmetros de validação. Sugere-se que as especificações estudadas sejam adotadas para o controle de impurezas contaminantes, contribuindo para garantir a qualidade, segurança e eficácia dos produtos veterinários de uso parenteral.

\section{REFERÊNCIAS}

ANDRADE, S.S. et al. Comparative evaluation of the human whole blood and human peripheral blood monocyte tests for pyrogens. International Journal of Pharmaceutics, v.265, p.115-124, 2003.

Ciência Rural, v.37, n.1, jan-fev, 2007. 
Tabela 3 - Resultados dos ensaios para geleificação e cromogênico do lisado de amebócitos do Limulus (LAL), em produtos veterinários.

\begin{tabular}{|c|c|c|c|c|}
\hline \multirow[b]{2}{*}{ Fármacos } & \multicolumn{3}{|c|}{ Teste do LAL } & \multirow[b]{2}{*}{ Resultado } \\
\hline & Limite de endotoxinas & Gel UE ml-1 & $\begin{array}{l}\text { Cromogênico UE } \\
\mathrm{ml}^{-1}\end{array}$ & \\
\hline Amoxicilina $150 \mathrm{mg} \mathrm{ml}^{-1}$ & $0,25 \mathrm{UE} / \mathrm{mg}^{2}$ & $<0,06$ & $<0,06$ & Aprovado \\
\hline Bromexina $30 \mathrm{mg} \mathrm{ml}^{-1}$ & $16 \mathrm{UE} / \mathrm{mg}^{1}$ & $<0,06$ & $<0,06$ & Aprovado \\
\hline Cetoprofeno $100 \mathrm{mg} \mathrm{ml}^{-1}$ & $1,7 \mathrm{UE} / \mathrm{mg}^{1}$ & $0,96-1,92$ & 1,26 & Aprovado \\
\hline Dexametasona $2 \mathrm{mg} \mathrm{ml}^{-1}$ & $100 \mathrm{UE} / \mathrm{mg}^{1}$ & $<0,06$ & $<0,06$ & Aprovado \\
\hline Dipirona $500 \mathrm{mg} \mathrm{ml}^{-1}$ & $0,7 \mathrm{UE} / \mathrm{mg}^{1}$ & $<0,06$ & $<0,06$ & Aprovado \\
\hline Enrofloxacino $25 \mathrm{mg} \mathrm{ml}^{-1}$ & $1 \mathrm{UE} / \mathrm{mg}^{1}$ & $<0,06$ & $<0,06$ & Aprovado \\
\hline Fenilbutazona $200 \mathrm{mg} \mathrm{ml}^{-1}$ & $0,125 \mathrm{UE} / \mathrm{mg}^{1}$ & $0,06-0,12$ & 0,09 & Aprovado \\
\hline Florfenicol 992 $\mathrm{mcg} \mathrm{mg}^{-1}$ & $0,125 \mathrm{UE} / \mathrm{mg}^{1}$ & $0,06-0,12$ & 0,10 & Aprovado \\
\hline Flumetasona $0,5 \mathrm{mg} \mathrm{ml}^{-1}$ & $400 \mathrm{UE} / \mathrm{mg}^{1}$ & $<0,06$ & $<0,06$ & Aprovado \\
\hline Furosemida $10 \mathrm{mg} \mathrm{ml}^{-1}$ & $3,5 \mathrm{UE} / \mathrm{mg}^{2}$ & $0,12-0,24$ & 0,17 & Aprovado \\
\hline Gentamicina $40 \mathrm{mg} \mathrm{ml}^{-1}$ & $1,67 \mathrm{UE} / \mathrm{mg}^{2}$ & $<0,06$ & $<0,06$ & Aprovado \\
\hline Heparina $5000 \mathrm{UI} \mathrm{ml}^{-1}$ & $0,03 \mathrm{UE} / \mathrm{UI}^{1}$ & $<0,06$ & $<0,06$ & Aprovado \\
\hline Levamisol $75 \mathrm{mg} \mathrm{ml}^{-1}$ & $1,33 \mathrm{UE} / \mathrm{mg}^{1}$ & $<0,06$ & $<0,06$ & Aprovado \\
\hline Metoclopramida $5 \mathrm{mg} \mathrm{ml}^{-1}$ & $5 \mathrm{UE} / \mathrm{mg}^{1}$ & $0,12-0,24$ & 0,13 & Aprovado \\
\hline Ocitocina $10 \mathrm{UI} \mathrm{ml} \mathrm{m}^{-1}$ & $50 \mathrm{UE} / \mathrm{UI}^{1}$ & $<0,06$ & $<0,06$ & Aprovado \\
\hline Xilazina $20 \mathrm{mg} \mathrm{ml}^{-1}$ & $16,6 \mathrm{UE} / \mathrm{mg}^{1}$ & $3,84-7,68$ & 4,88 & Aprovado \\
\hline Associação C & 0,01 UE/100 UI Penicilina $\mathrm{G}^{1}$ & $61-122$ & 83,6 & Reprovado \\
\hline Associação D & 0,01 UE/100 UI Penicilina $\mathrm{G}^{1}$ & $<0,06$ & $<0,06$ & Aprovado \\
\hline Associação E & $0,015 \mathrm{UE} / \mathrm{mg}^{1}$ & $491-983$ & 500,24 & Reprovado \\
\hline Associação F & $0,2 \mathrm{UE} / \mathrm{mg}^{1}$ & $<0,06$ & $<0,06$ & Aprovado \\
\hline Associação G & $0,3 \mathrm{UE} / \mathrm{mg}^{1}$ & $<0,06$ & $<0,06$ & Aprovado \\
\hline
\end{tabular}

${ }^{1}$ Calculado - DFI; ${ }^{2} \mathrm{EP} ., 2002 ; \mathrm{UE}=$ unidades endotóxicas.

BRASIL. Ministério da Agricultura, Pecuária e Abastecimento. Decreto n. 5.053 de 22 de abril de 2004. Aprova o regulamento de fiscalização de produtos de uso veterinário e dos estabelecimentos que os fabriquem ou comerciem, e dá outras providências. Diário Oficial da União, Brasília, 23 abr. 2004.

BRITISH PHARMACOPOEIA (VETERINARY). London: Her Majesty's Stationary Office, 2003. 218p.

EUROPEAN PHARMACOPOEIA, 4 ed. Strasbourg: European Department for the Quality of Medicines, 2002. 561p.

FARMACOPÉIA BRASILEIRA, 4.ed. Atheneu: São Paulo, 1988. V.5.1.2.

FENNRICH, S. et al. Detection of endotoxins and others pyrogens using human whole blood. Developments in Biological Standardization, v.101, p.131-139, 1999.

HENDERSON, B. et al. Bacterial modulins: a novel class of virulence factors which cause host tissue pathology by inducing cytokine synthesis. Microbiological Research, v.60, n.2, p. 316-341, 1996.

HOFFMANN, S. et al. Optimisation of pyrogen testing in parenterals according to different pharmacopoeias by probabilistic modeling. Journal of Endotoxin Research, v.11, n.1, p.25-31, 2005.

LEVIN, J.; BANG, F.B. The role of endotoxin in the extracellular coagulation of Limulus blood. Bulletin of the Johns Hopkins Hospital, v.115, p.265-274, 1964.

KLUGER, M.J. Fever: role of pyrogens and cryogens. Physiological Reviews, v.71, n.1, p.93-127, 1991.

MOESBY, L. et al. A comparative study of Mono Mac 6 cells, isolated mononuclear cells and limulus amoebocyte lysate assay in pyrogens testing. International Journal of Pharmaceutics, v.191, p.141-149, 1999.

POOLE, S.; GAINES DAS, R.E. Towards a 'human pyrogen test'. European Journal of Parenteral Science, v.6, n.2, p.63-64, 2001.

RIETSCHEL, E.T. et al. Bacterial endotoxin: molecular relationships of structure to activity and function. FASEB Journal, v.8, p.217-225, 1994.

SILVEIRA, R.L. et al. Comparative evaluation of pyrogens tests in pharmaceutical products. Brazilian Journal of Microbiology, v.35, p.48-53, 2004.

Ciência Rural, v.37, n.1, jan-fev, 2007. 